\title{
Patient and professional views of open access hysterosalpingography for the initial management of infertility in primary care
}

\author{
Scott Wilkes, Greg Rubin, Ann Crosland, Nicola Hall and Alison Murdoch
}

\section{ABSTRACT}

Background

Hysterosalpingography (HSG) is recommended as a firstline investigation for tubal assessment of infertile women. This investigation is not routinely available to GPs.

Aim

To explore the perceptions and attitudes of patients and health professionals to open access HSG for the initial management of infertile couples in general practice.

Design of study

A nested qualitative study using in-depth interviews with GPs, fertility specialists, and infertile couples.

Setting

Northumberland, Newcastle upon Tyne, North Tyneside, South Tyneside, and Gateshead.

\section{Method}

Participants were 39 interviewees: 12 GPs, five fertility specialists, and 13 infertile couples (nine interviewed with their partner).

\section{Results}

Four themes emerged: personal factors; will it benefit patients, GPs, and fertility specialists?; professional factors; does it fit the role of a GP?; local context; do the skills exist in general practice?; and wider context; will it benefit the NHS? GPs who had used open access HSG, felt it was appropriate for general practice and would continue to use the service. All GPs, fertility specialists, and infertile couples who had experienced open access HSG wished the service to remain in place. The main barriers to its uptake were: infrequency with which infertility presents; lack of clarity on perceived responsibilities; difficulty keeping up to date, including assimilating guidelines; low clinical priority; and lack of support in authoritative guidance.

\section{Conclusion}

Providing GPs with open access to HSG would allow a full initial assessment of the infertile couple and refer women with blocked tubes directly to tertiary care. While there is general support for the provision of such a facility, the majority of GPs perceive its use as being by a limited number of GPs who have a special interest in infertility. The study findings can inform future development of infertility services at the interface between primary and secondary/tertiary care.

\section{Keywords}

attitudes; family practice; health services accessibility; hysterosalpingography; infertility; perceptions; primary health care.

\section{INTRODUCTION}

Infertility affects approximately one in six couples during their lifetime. ${ }^{1,2}$ Each GP can expect to see on average one to two infertile couples each year, ${ }^{2,3}$ and will investigate approximately half of these with endocrine blood tests and semen analysis..$^{3-5}$ The Royal College of Obstetricians and Gynaecologists' guidelines defined a role for GPs in the initial management of infertile couples, which excluded any form of tubal assessment. ${ }^{6}$ The National Institute for Health and Clinical Excellence (NICE) guideline refined these and advocated hysterosalpingography (HSG) screening for tubal occlusion as part of the initial assessment. ${ }^{7}$ As part of a pragmatic cluster randomised controlled trial of its impact on fertility management, open access to HSG was made available to 36 general practices in north-east England. This study explored the perceptions and attitudes of patients and professionals to open access HSG for the initial management of infertile couples in general practice.

S Wilkes, PhD, MRCGP, GP/clinical research fellow; G Rubin, FRCGP, professor, head of department and part-time GP;

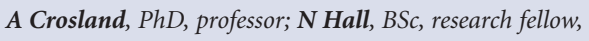
Centre for Primary and Community Care, School of Health Natural and Social Sciences, University of Sunderland. A Murdoch, BSc, MD, FRCOG, professor, consultant in reproductive medicine and head of department, Newcastle Fertility Centre at LIFE, BioScience Centre, International Centre for Life, Newcastle upon Tyne.

Address for correspondence

Dr Scott Wilkes, Centre for Primary and Community Care, School of Health Natural and Social Sciences, Priestman Building, Green Terrace, University of Sunderland, SR2 3PZ. E-mail: scott.wilkes@sunderland.ac.uk

Submitted: 9 August 2008; Editor's response: 27 October 2008; final acceptance: 17 December 2008.

(c)British Journal of General Practice 2009; 59: 336-342. DOI: 10.3399/bjgp09X420608 


\section{METHOD}

\section{Design}

A nested qualitative study using in-depth interviews was used to explore the experiences, attitudes, and perceptions of GPs, fertility specialists, and infertile couples. Understanding of open access HSG from the participants' perspectives ${ }^{8}$ was sought using both inductive and deductive approaches. ${ }^{9}$ Themes from a previous focus group study informed the initial topic guide..$^{10} \mathrm{~A}$ grounded approach ${ }^{11}$ allowed the exploration and development of the emerging themes. ${ }^{12}$

\section{Setting}

Interviews were conducted with health professionals at their workplace, and with infertile couples at their GP's surgery. GPs, fertility specialists, and infertile couples from Tyneside and Northumberland were invited to take part.

\section{Participants}

Thirty interviews were conducted, of which 12 were with GPs (GP 1 to GP 12), five with fertility specialists (S1 to S5), and 13 with infertile couples (22 interviewees: nine couples and four women: F1 to $\mathrm{F} 13$, with males denoted by $\mathrm{M}$ ). Participant characteristics are shown in Table 1 (accompanying male partners prefixed by $\mathrm{M}$ ). Interviewees were identified in the course of a pragmatic cluster randomised controlled trial evaluating open access HSG for the initial management of infertility in general practice (OATS trial). ${ }^{13}$ Confidentiality was assured and the process of the interview explained. A topic guide (Box 1) informed the initial interviews and was revised as the study progressed. The interviews were audiotaped and fully transcribed, and quotes from the transcripts were anonymised.

\section{Sampling}

A convenience sample of five specialists, each the head of fertility services within their respective hospitals, were approached for interview and all agreed to participate. Three provided tertiary-level

\section{How this fits in}

GPs believe that they do have a role and responsibility in management of the

initial stages of the consultation with infertile couples. Open access

hysterosalpingography is not widely available but is recommended as a first-line investigation for infertile women not known to have comorbidities. Some GPs

are willing to use open access hysterosalpingography, and this role for GPs has support from fertility specialists and infertile couples.

fertility services and two were general gynaecologists with an interest in infertility management within the secondary care setting, providing non-HFEA (Human Fertilisation and Embryology Authority)-licensed fertility services. The OATS trial had 203 GPs and 670 infertile couples in 58 participating practices. Theoretical sampling was used to inform emerging themes, with an attempt to search for deviant cases to disprove emerging themes. Sampling proceeded until no further categories or new information emerged from the interviews. ${ }^{11,14}$ GPs and infertile couples who had and who had not experienced open access HSG, and who had and had not achieved a pregnancy were interviewed. Couples were encouraged to attend the interview together.

\section{Analysis \\ Data analysis proceeded as the interviews progressed. ${ }^{11}$ Independent analyses were carried out with the findings discussed and emerging themes negotiated following each round of interviews. Constant comparison of the new interview data and previous interview data continually modelled and remodelled the emerging theory. ${ }^{11}$ Data were categorised into emerging themes and a concept diagram constructed. Open code 'labelling' of the data preceded the categorisation of the data (axial coding). ${ }^{15}$ Finally, selective coding identified core categories/themes, which were refined and related, giving an overall explanation of the data. ${ }^{12} \mathrm{~A}$ transcription and}

Table 1. Participant characteristics.

\begin{tabular}{|c|c|}
\hline Characteristics & Participants \\
\hline GP had access to HSG and used it & GP4a, GP11, GP12 \\
\hline GP had access to HSG and did not use it & GP1"a, GP3, GP5, GP8 ${ }^{a}$, GP9 $^{a}$, GP10 \\
\hline GP did not have access to HSG & GP2, GP6 ${ }^{a}, \mathrm{GP}^{\mathrm{a}}$ \\
\hline Fertility specialist offered HFEA-licensed fertility treatments & $\mathrm{S} 1^{\mathrm{a}}, \mathrm{S} 5$ \\
\hline Fertility specialist offered non-HFEA-licensed fertility treatments & $S 2^{\mathrm{a}}, \mathrm{S} 3^{\mathrm{a}}, \mathrm{S} 4^{\mathrm{a}}$ \\
\hline Infertile couples experienced open access HSG & F2, F4 \& M4 $4^{a}, F^{a} \& M 5, F 6^{a}, F 8, F 11^{a} \& M 11, F 12 \& M 12, F 13$ \\
\hline Infertile couples did not experience open access HSG & $\mathrm{F} 1 \& \mathrm{M} 1, \mathrm{~F} 3$ \& $\mathrm{M} 3, \mathrm{~F} 7 \& \mathrm{M} 7, \mathrm{~F} 9 \& \mathrm{M} 9, \mathrm{~F} 10^{\mathrm{a}} \& \mathrm{M} 10$ \\
\hline
\end{tabular}




\section{Box 1. Initial topic guide for infertile couple and professional interviews.}

What do you know/think/see/feel about NHS provision of infertility services?

What do you know/think/see/feel about the quality of infertility services?

What do you know/think/see/feel about the specialist's role in infertility?

What do you know/think/see/feel about the GP's role in infertility? Should GPs investigate, use clomifene, and/or have open access HSG? What about uncertainty and lack of knowledge, consistency of approach?

Whose job is it to manage the infertile couple?

- Access to services: what do you know/think/see/feel about GPs'/specialists' accessibility?

Changes in perceptions and attitudes over time

What are your experiences of infertility management?

What do you know/think/see/feel about NICE guidelines?

What do you know/think/see/feel about open access HSG?

What do you know/think/see/feel about self-help or support groups?

$H S G=$ hysterosalpingography
HSG. The main barriers cited were infrequent exposure to infertile couples, subsequent inability to rehearse the necessary skills, resultant lack of confidence, and assuming a low priority for GPs:

'Sadly for infertility I think the problem is we don't see much of it, therefore it is not classed as a huge priority.' (GP6)

GPs who did not use or wish to use open access HSG felt it would create more work, although minimal, and suggested it should be managed by one GP on behalf of a group of GPs within the primary care setting. There was concern that many GPs, lacking interest, would opt for the path of least resistance and refer directly without full initial investigation:

'Whether my colleagues would use it or not, I don't know. I tend to think the majority of them might cut to the referral straight away.' (GP4)

Fertility specialists in both secondary and tertiary care highlighted the benefits for themselves of receiving couples having had the initial investigations performed. It enabled a diagnosis and management plan to be made at the first specialist appointment and in some cases couples were listed for in vitro fertilisation (IVF) immediately. There was some concern about inappropriate use of HSG, but this was largely rationalised with access to HSG being criteria driven. Non-HFEAlicensed secondary care fertility specialists who did not offer IVF or intracytoplasmic sperm injection highlighted that couples with tubal pathology would be appropriately screened out and referred to an HFEA-licensed fertility unit:
Figure 1. Concept diagram of themes emerging from interview data. interpreted summary of the transcripts was given to participants to allow for feedback on the are shown in Figure 1 and are presented in the

\section{RESULTS}

Personal factors: will it benefit patients, GPs, and fertility specialists?

Most GPs felt that open access HSG would speed up the investigation process for infertile couples but felt uncomfortable with organising an open access

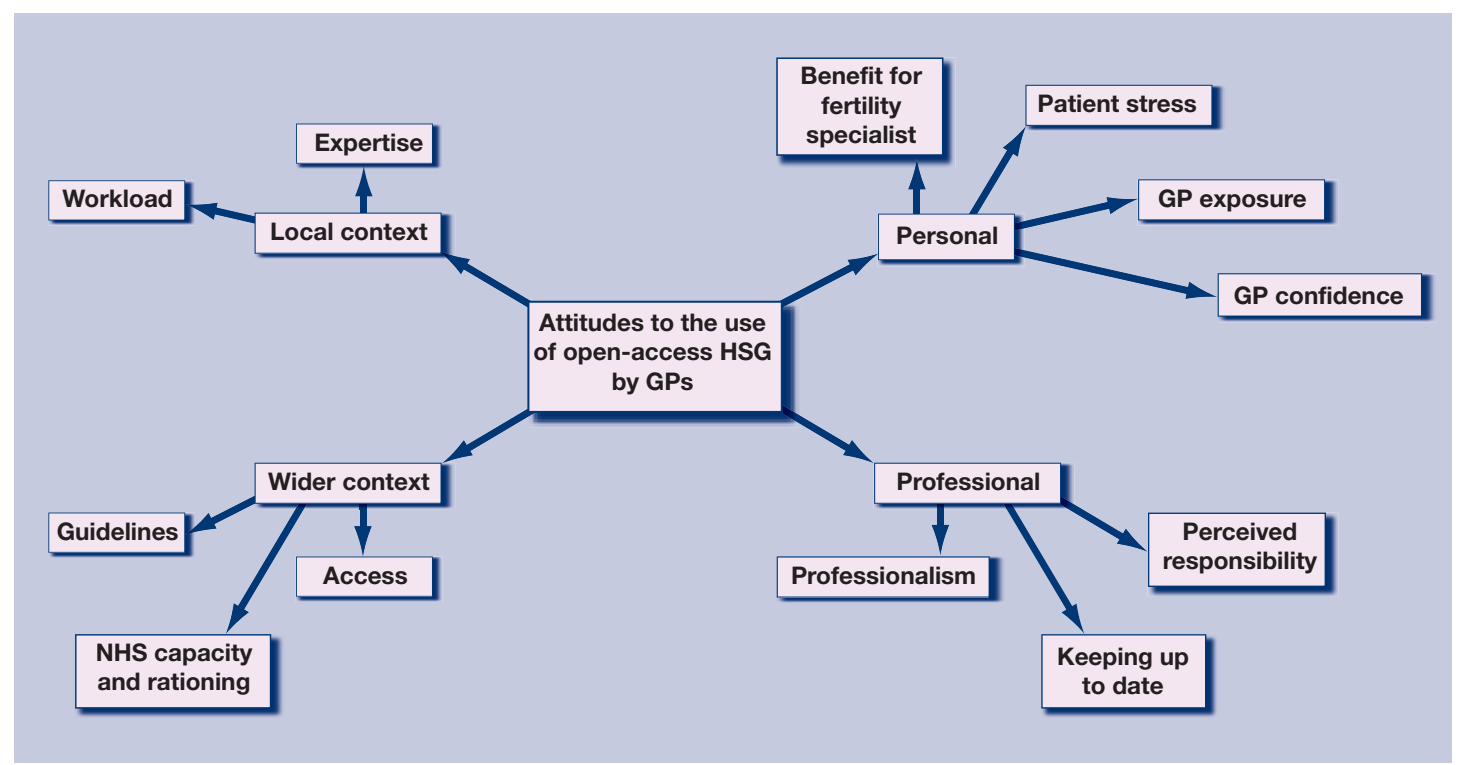


'It would [be useful having the GP organise the $\mathrm{HSG}$ ] because again it is one of the things that slows us down. Every couple that comes up, gets an initial appointment, their bloods, their semen analysis, and an HSG all done according to their circumstances. If at the first appointment all of those are available, that will cut down the waiting list. I think it would be great, because they come up and you would be much nearer to the outcome.' (S4)

An additional benefit described might be the appropriate delay of referral for young couples with normal investigations and a working diagnosis of unexplained infertility. Patients who experienced open access HSG were positive about the experience, saying that it reduced the stress and anxiety of having to wait to see a specialist to find out why they were having difficulty conceiving. They felt that the GP 'getting the ball rolling' speeded up their access to fertility services. Some patients who were subsequently referred privately found a decrease in their investigation costs:

\section{'I got in for my HSG within a week.' (F11) \\ 'It put my mind at ease straight away.' (F5)}

\section{Professional factors: does it fit the role of a GP?}

Half of the GPs interviewed felt that it was within their remit to organise an HSG and had the expertise to do so, but were concerned that pressure upon their time would inevitably lead to Quality and Outcomes Framework contract-based activity over the adoption of a new service. GPs who had used the service felt that it was appropriate, while some of those who had not used it felt that this was not their responsibility. Some GPs expressed concerns about difficulty keeping up to date and possessing the necessary skills to perform additional investigations. The initial investigations, organising the blood tests and semen test, including HSG, were viewed as basic investigations by the majority of GPs and within their professional role:

'Well I think it is appropriate [open access HSG], yes, it is part of the basic investigations.' (GP9)

Fertility specialists acknowledged that patients have an enduring relationship with the GP, which is beneficial to the couple at the beginning of, during, and after treatment. They felt that open access HSG was an appropriate investigation to organise within the primary care setting, but secondary care fertility specialists were concerned that the couples may not be fully investigated and/or managed before being passed on to tertiary care. There were balanced views on the perceived responsibility for organising the HSG:

'I think primary care can organise the HSG. It's part of the first lot of investigations and it's the GP who sees the patients at the beginning and indeed throughout their lives. If they don't do it then someone else will have to do it. If it's appropriately done I don't think it matters who organises it.' (S1)

All couples who experienced open access HSG assessment were surprised to learn that this was a service that not all GPs might offer. They felt that this should fall within their professional remit. The majority of couples who did not experience open access HSG felt that it was within the capabilities of the GP, but a minority would prefer direct referral to a specialist, to 'someone who knows what they are doing':

'Well I think she was particularly good, I think all GPs should be able to do that [sperm tests, blood tests, and open access HSG] for their patients.' (F5)

\section{Local context: do the skills exist within general practice to request HSG?}

There was a lot of debate about whether the necessary expertise existed in general practice to take on open access HSG. It was another new service with more guidelines that GPs were unfamiliar with. A minority of GPs felt it would fall within the remit of a GP with a special interest, ${ }^{16}$ due to the relative infrequency of presentation to all GPs, while the majority felt it was suited to a GP with an informal interest within the practice setting. Open access HSG required some prior assessment and laboratory investigations and would not have a significant impact on workload:

'Some of the partners were very keen on it [open access HSG], but this doesn't actually give us any more work, apart from filling in the form, so it is not a difficult one.' (GP1)

There was some difficulty with interpretation of the HSG test result and whether the next appropriate action was delayed referral, secondary or tertiary referral, or ovulation induction. Fertility specialists and some GPs did not perceive that any expertise was required to organise an open access HSG: 
'What expertise do you need? You need a pen and fill in a form.' (S2)

'Very easy to use, yes. Yes, it is very straightforward with a tick box and if any don't kind of match then you just have to refer up.' (GP4)

Similarly, most couples felt that most but not all GPs had the necessary expertise to manage the initial stages of the infertile couple, including organisation of HSG:

'I think that somebody should have a bit more information, a bit more expertise and knowledge rather than all GPs being able to refer [for open access HSG], I think so.' (F10)

Other infertile couples felt that these skills may not exist within general practice:

'It is always nice to see the clinical consultants, these people specialise in this particular subject, therefore would you get the tyres for your cars changed at McDonalds?' (F6)

\section{Wider context: does open access HSG fit within the NHS organisation?}

Most participants felt that open access HSG would direct referrals more appropriately. The resultant benefit may be decreased commissioning costs through a decrease in unnecessary or wrongly directed referrals, particularly women with blocked tubes being referred to non-HFEA-licensed secondary care fertility units:

'A contract can be changed or renegotiated. It is bureaucracy isn't it? If a GP does an HSG and it says both tubes are blocked, the patient needs IVF'' (S3)

Guidelines were seen as enabling practitioners to work effectively and offering some indemnity through their application, although GP-initiated HSG investigation is not currently supported (or refuted) in existing guidelines:

'One of the uses of guidelines, probably more than telling me what to do, is actually if you are taking things a little bit further, it will offer you some protection.' (GP7)

The capacity of tertiary care to take on extra work as a result of increased primary care referrals following HSG assessment was questioned by both GPs and fertility specialists, but most agreed that secondary care would continue to have a role, for example in simpler forms of ovulation induction:

'I think it feels as though the people who are running things like IVF are saying that they haven't got the staff and capability to run these things yet.' (GP1)

Patients felt that access to advanced reproductive technologies was rationed and it was not an NHS priority. This was linked to the perception that infertility was not a disease:

'Obviously, priority has to be treatment of ill people first I would say.' (M4)

All GPs, fertility specialists, and infertile couples who had experienced open access HSG wished the service to remain in place, including some GPs who had not experienced it:

'I think it would be better if it was available rather than not, you know.' (GP8)

Not all GPs were keen to have access to it personally.

\section{DISCUSSION}

\section{Summary of main findings}

All GPs who used open access HSG and some of those who did not use the service wished it to continue to be available. Not all GPs wished to use open access HSG or investigate infertility. Fertility specialists felt that open access HSG was part of the initial investigations and could be arranged in general practice. Infertile couples who experienced open access HSG were positive about the experience and felt it had speeded their journey towards a diagnosis and management plan. The main barriers to the use by GPs of open access HSG were the infrequency with which infertility presents; lack of clarity on perceived responsibilities; difficulty keeping up to date, including assimilating guidelines; low clinical priority; and lack of support in authoritative guidance.

\section{Strengths and limitations of the study}

The interviews allowed an in-depth exploration of the complex issues associated with infertility management within the NHS. The interviewer, a GP, had been involved in the service design and this may have resulted in interviewer bias. However, his in-depth knowledge of the subject and peer relationship with professionals allowed questioning to probe more deeply. The 30 interviews were with a heterogeneous group with 13 infertile couples (22 
interviews: nine couples and four women), 12 GPs, and five fertility specialists. The interviews gave insights into attitudes and perceptions but these cannot be translated into behaviours. They represent the views of patients and working health professionals dealing with infertility within the NHS, and may be transferable. ${ }^{15}$ The results have a high degree of credibility, being an actual account of the experiences, attitudes, and perceptions of the participants. ${ }^{15}$ Although not within the scope of this study, the views of NHS service commissioners would have been beneficial.

\section{Comparison with existing literature}

The introduction of a new technology, such as open access HSG, into general practice requires an understanding of the potential barriers to its uptake..$^{17,18}$ Barriers to the introduction of open access gastroscopy included funding stream cuts, a fear of increased demand on secondary care, and negative consultant attitudes, ${ }^{19}$ but it has since become established in routine practice..$^{20}$ Barriers to infertility management in primary care $^{10}$ are similar to those encountered in open access echocardiography: uncertainty and lack of knowledge; lack of confidence in establishing an accurate diagnosis; difficulty understanding the implications of the result; lack of access to diagnostic facilities; a rapidly changing complex field; and poor communication between primary and secondary care. ${ }^{21}$

While there are no published reports of the attitudes of patients or professionals to open access HSG, there have been three surveys exploring the role of GPs in infertility management more generally. Half of GPs in one survey said they were an important source of information and advice on infertility treatments. ${ }^{22}$ However, other studies have shown that some GPs consider infertility management to be outside their remit. ${ }^{23,24}$

In contrast, there is an expectation by specialists that GPs make a full initial assessment, refer appropriately, ${ }^{25,26}$ and are able to advise on treatment risks and outcomes. ${ }^{27-29}$

Patients also expect their GP to provide support, advice, investigation, and treatment, ${ }^{30}$ and are generally satisfied with the care they receive..$^{31,32}$

\section{Implications for future research and clinical practice}

If HSG is to be made more widely available to GPs, it may best be as part of a care pathway governed by the fulfilment of clinical criteria. ${ }^{33}$ Future research should focus on the evaluation of implementation strategies, paying attention to the barriers identified in this study.

\section{Funding body}

We would like to acknowledge the NHS National Coordinating Centre for Research Capacity Development who funded this work through a National Institute for Health Research (NIHR) award held by Dr Scott Wilkes: Primary Care Researcher Development Award, National Coordinating Centre for Research Capacity Development, Leeds Innovation Centre, Leeds. All researchers involved in the production of this paper are independent from the funder

\section{Ethical approval}

Ethical approval was granted from Newcastle and North Tyneside as the main REC with SSA approval from Northumberland, Gateshead, and South Tyneside Local Research Ethics Committees. Approval was also granted from Sunderland University Research Ethics Committee

\section{Competing interests}

The authors have stated that there are none

\section{Acknowledgements}

Thanks to the study sponsor, Sunderland University. Academics within the university contributed to the study design; collection, analysis, and interpretation of data; production of the paper; and the decision to submit the article for publication.

\section{Discuss this article}

Contribute and read comments about this article on the Discussion Forum: http://www.rcgp.org.uk/bjgp-discuss

\section{REFERENCES}

1. Hull MG, Glazener CM, Kelly NJ, et al. Population study of causes, treatment, and outcome of infertility. BMJ 1985; 291(6510): 1693-1697.

2. Templeton A, Fraser C, Thompson B. The epidemiology of infertility in Aberdeen. BMJ 1990; 301(6744): 148-152.

3. Wilkes $\mathrm{S}$, Jones K. Retrospective review of the prevalence and management of infertility in women in one practice over a five year period. Br J Gen Pract 1995; 45(391): 75-77.

4. Das S, Chin KA. A study of pre-referral evaluation of infertile couples. J Obstet Gynaecol 2003; 23(1): 70.

5. Nicopoullos JD, Croucher CA. Audit of primary care and initial secondary care investigations set against RCOG guidelines as standard in cases of subfertility. J Obstet Gynaecol 2003; 23(4): 397-401.

6. Royal College of Obstetricians and Gynaecologists. Royal College of Obstetricians and Gynaecologists evidence-based clinical guidelines. Guideline Summary No. 2: the initial investigation and management of the infertile couple. BJU Int 1999; 83(6): 636-640.

7. National Institute for Clinical Excellence. Fertility: assessment and treatment for people with fertility problems. Clinical guideline 11. London: National Institute for Clinical Excellence, 2004.

8. Mays N, Pope C. Qualitative research: observational methods in health care settings. BMJ 1995; 311(6998): 182-184.

9. Blaikie N. Approaches to social inquiry. Cambridge: Polity Press, 1993.

10. Wilkes S, Hall N, Crosland A, et al. General practitioners' perceptions and attitudes to infertility management in primary care: focus group study. J Eval Clin Pract 2007; 13(3): 358-363.

11. Glaser B, Strauss A. The discovery of grounded theory. Chicago: Aldine, 1967.

12. Strauss ACJ. Basics of qualitative research. Grounded theory procedures and techniques. Newbury Park: Sage, 1990.

13. Wilkes S. Evaluation of open access HSG in the initial management of infertility in primary care. $\mathrm{PhD}$ thesis, University of Sunderland, 2007.

14. Pope C, Mays N. Qualitative research: reaching the parts other methods cannot reach: an introduction to qualitative methods in health and health services research. BMJ 1995; 311(6996): 42-45.

15. Lincoln Y, Guba E. Naturalistic enquiry. Newbury Park: Sage, 1985.

16. Jones R, Bartholomew J. General practitioners with special clinical interests: a cross-sectional survey. Br J Gen Pract 2002; 52(483): 833-844.

17. Bosch $\mathrm{M}$, van der Weijden $\mathrm{T}$, Wensing $\mathrm{M}$, et al. Tailoring quality improvement interventions to identified barriers: a multiple case analysis. J Eval Clin Pract 2007; 13(2): 161-188. 
18. Campbell NC, Murray E, Darbyshire J, et al. Designing and evaluating complex interventions to improve health care. BMJ 2007; 334(7591): 455-459.

19. Bramble MG, Cooke WM, Corbett WA, et al. Organising unrestricted open access gastroscopy in South Tees. Gut 1993; 34(3): 422-427.

20. Silcock JG, Bramble MG. Open access gastroscopy: second survey of current practice in the United Kingdom. Gut 1997; 40(2): 192-195.

21. Fuat A, Hungin AP, Murphy JJ. Barriers to accurate diagnosis and effective management of heart failure in primary care: qualitative study. BMJ 2003; 326(7382): 196

22. Morrison J. The management of involuntary childlessness. Br J Gen Pract 1997; 47(415): 69-70.

23. Souter VL, Penney G, Gorman DR. A survey of infertility practices in primary care in Scotland. Br J Gen Pract 1997; 47(424): 727-728.

24. Ittner E, Himmel W, Kochen MM. German family physicians' attitudes toward care of involuntarily childless patients. Fam Med 2000; 32(2): 119-125.

25. Lilford R, Young G. How general practitioners can help subfertile couples. BMJ 1992; 305(6866): 1376-1377.

26. Taylor A. ABC of subfertility: extent of the problem. BMJ 2003;
327(7412): 434-436

27. Cahill DJ, Wardle PG. Management of infertility. BMJ 2002; 325(7354): 28-32

28. Himmel W, Ittner E, Kochen MM, et al. Management of involuntary childlessness. Br J Gen Pract 1997; 47(415): 111-118.

29. Taylor A. ABC of subfertility. Making a diagnosis. BMJ 2003; 327(7413): 494-497.

30. Kerr J, Brown C, Balen AH. The experiences of couples who have had infertility treatment in the United Kingdom: results of a survey performed in 1997. Hum Reprod 1999; 14(4): 934-938.

31. Halman LJ, Abbey A, Andrews FM. Why are couples satisfied with infertility treatment. Fertil Steril 1993; 59(5): 1046-1054.

32. Schmidt L, Holstein BE, Boivin J, et al. High ratings of satisfaction with fertility treatment are common: findings from the Copenhagen Multi-centre Psychosocial Infertility (COMPI) Research Programme. Hum Reprod 2003; 18(12): 2638-2646.

33. Wilkes S, Murdoch A, Rubin G, et al. Investigation of infertility management in primary care with open access hysterosalpingography (HSG): a pilot study. Hum Fertil 2006; 9(1): $47-51$. 